\title{
Eosinophilic Meningitis without Peripheral Eosinophilia
}

\author{
Dokyung Lee Sang-Hwa Lee Sung Sang Yoon Tae-Beom Ahn \\ Department of Neurology, Kyung Hee University College of Medicine, Seoul, Korea
}

\section{Dear Sir,}

Eosinophilic meningitis (EM) may be diagnosed if there are more than 10 eosinophils (Eo)/ $\mu$ l or $10 \%$ leukocytes in the cerebrospinal fluid (CSF) [1]. EM is commonly associated with peripheral eosinophilia (PEo), and the most common cause of EM is parasitic infestation [2]. Few patients with EM have presented without PEo, and in those patients parasite infestation and drugs were identified as the culprits [3-5]. There have been no reports of idiopathic EM without PEo.

\section{Case Reports}

\section{Case 1}

A 30-year-old female was admitted to the hospital because of sudden-onset right facial palsy. She had neither fever nor headache. Her medical history, including medications such as analgesics and antibiotics, was unremarkable.

On neurologic examination, she had sensorineural hearing loss of the right ear on the Weber and Rinne tests in addition to a peripheral type right facial palsy. Impedance and pure tone audiometry showed no abnormalities. Two days after admission, she complained of double vision. The red glass test revealed right lateral rectus palsy. No other abnormal neurologic features were noted.
PEo was within normal limits $(100 / \mu 1$, $0.7 \%)$. CSF analysis showed a value of 26 white blood cells (WBCs) per microliter with predominant Eo (91\%) (table 1) and the CSF/serum albumin ratio [CSF albumin $(\mathrm{mg} / \mathrm{dl}) /$ serum albumin $(\mathrm{g} / \mathrm{dl})$ ] was normal (4.91). Extensive workups for infectious diseases including viral, bacterial and fungal agents were unremarkable. No malignant cells were detected in the CSF. Parasite studies such as stool examination and enzyme-linked immunosorbent assay (ELISA) for parasite infestations including neurocysticercosis, paragonimiasis, and sparganosis were negative. Brain magnetic resonance imaging (MRI) with gadolinium enhancement was normal.

Clinical symptoms improved with methylprednisolone ( $48 \mathrm{mg} /$ day p.o. for 5 days). No Eo was detected in the follow-up CSF study after 13 days. No additional neurologic illness appeared for over 3 years.

\section{Case 2}

A 70-year-old woman with diabetes presented with fever and headache that had persisted for 2 days. She had not taken any medications except her usual drugs for diabetes. Her neurologic examination was normal except for a finding of neck stiffness.
PEo was absent $($ Eos $=30 / \mu l, 0.7 \%)$. CSF examination showed $150 / \mu$ l WBCs with $78 \%$ Eo (table 1). The patient's CSF/ serum albumin ratio was elevated (22.95). The CSF oligoclonal band was absent. Diagnostic workups for viral, bacterial, parasitic and fungal diseases including a stool examination and ELISA for parasites were unremarkable. Brain MRI with gadolinium enhancement was normal.

Her clinical symptoms spontaneously disappeared without any specific treatment such as steroid pulse therapy. A follow-up CSF study was normal. She reported no neurologic illness afterwards.

Case 3

A 23-year-old female was admitted to the hospital for headache and fever. She had no significant medical history and did not take any medications before her illness.

Although she was normal on neurologic examination, a CSF study was performed due to severe headache, showing $450 / \mu l$ WBCs with predominant Eo (43\%). PEo was absent $(370 / \mu l, 3 \%)$ (table 1$)$. Further workups for causative agents were unremarkable, including stool and ELISA studies for parasite infestation. An enhanced brain MRI was normal. Serologic tests showed the presence of anti-SSA antibodies (60 and $52 \mathrm{Kd}$ ) without any symp-

\section{KARGER}

Fax +4161306 1234 E-Mail karger@karger.ch www.karger.com
(C) 2012 S. Karger AG, Basel

0014-3022/12/0674-0217\$38.00/0

Accessible online at: www.karger.com/ene
Tae-Beom Ahn

Department of Neurology, Kyung Hee University Hospital

No. 1 Hoegi-dong, Dongdaemun-gu

Seoul 130-702 (Korea)

Tel. +82 2958 8448, E-Mail ricash@ hanmail.net 
Table 1. Major clinical manifestations and laboratory findings of previously reported cases of EM without PEo

\begin{tabular}{|c|c|c|c|c|c|c|c|}
\hline Related conditions of EM & \multicolumn{2}{|l|}{ Blood } & \multicolumn{4}{|l|}{ CSF } & Major clinical manifestations \\
\hline Ciprofloxacin [3] & 6,700 & $402(6.0)^{\mathrm{c}}$ & 54 & $52 / 109$ & 147 & 24 & fever, headache, neck stiffness \\
\hline Ibuprofen [4] & 11,400 & $114(1.0)^{\mathrm{c}}$ & 60 & $44 / 99$ & 576 & 60 & fever, headache, neck stiffness \\
\hline $\begin{array}{l}\text { Ventriculoperitoneal shunt, } \\
\text { Coxsackie B4 virus [11] }\end{array}$ & 10,600 & $0(0)$ & 140 & $76 / 107$ & 407 & 11 & prolonged generalized seizure, fever, nuchal rigidity \\
\hline HL [7] & NA & $0(0)$ & 72 & $46 / \mathrm{NA}$ & 22 & 35 & HL stage IIB, fever, headache \\
\hline HL $[8]$ & NA & $0(0)$ & 392 & $10 / \mathrm{NA}$ & 490 & 80 & Headache, weakness, diplopia \\
\hline HL [9] & 6,500 & $0(0)$ & $\begin{array}{l}\text { mildly } \\
\text { elevated }\end{array}$ & NA & 133 & PC & HL stage IIA, fever, generalized seizure \\
\hline None (case 1 ) & 11,800 & $100(0.7)$ & 29 & $66 / 170$ & 26 & 91 & facial palsy, sensorineural hearing loss, diplopia \\
\hline None (case 2) & 4,500 & $30(0.7)$ & 115 & $84 / 134$ & 150 & 78 & fever, headache \\
\hline
\end{tabular}

$\mathrm{NA}=$ Not available; $\mathrm{PC}=$ pathologically confirmed (exact Eo count was not specified). ${ }^{\mathrm{a}}$ Values are CSF/serum except for ${ }^{\mathrm{b}} \mathrm{CSF} / \mathrm{serum}$ ratio; ${ }^{\mathrm{c}}$ calculated number of Eos.

toms or signs suggesting connective tissue diseases such as Sjögren's syndrome. Antinuclear antibodies and anti-Sm antibodies were absent.

Conservative treatment with adequate hydration and analgesics (ketorolac and tramadol hydrochloride) was administered. Her symptoms and follow-up CSF study improved (Eo 27\% and WBC count $140 / \mu 1)$. She suffered no neurologic problems over the next 2 years.

\section{Discussion}

The predominance of Eo in CSF was not accompanied by PEo in our series. As no specific etiologies were identified and latent etiologies were excluded by benign clinical courses and uneventful followups, our cases were designated as idiopathic EM without PEo.

Symptomatic cases of EM without PEo are rarely reported in the literature [3-9]. Etiologies include Angiostrongylus cantonensis infestation, Hodgkin's lymphoma (HL), and medications such as ciprofloxa- cin and ibuprofen. In a case series of $A$. cantonensis infestations, only 1 out of 17 cases could be classified as EM without PEo [5]. Although Coxsackie B4 virus infection was found in one patient with a ventriculoperitoneal shunt, intra-ventricular administration of antibiotics could not be excluded as the cause of isolated CSF Eos [10]. In HL, EM without PEo was associated with CNS invasion and poor prognosis [6-9].

The blood-brain barrier may limit Eo proliferation within the CSF in cases receiving intra-ventricular drugs [11]. In $\mathrm{HL}$, some reports have indicated that isolated CSF Eos may be mediated by interleukin production by tumor cells such as IL-5 and/or IL-3 [12]. However, the pathomechanism of isolated Eo proliferation within CSF remains uncertain in non-HL cases and in our idiopathic cases. Although immunologic derangement could be considered in case 3 , isolated CSF Eos was not explainable by peripheral anti-SSA antibody in addition to the presence of the antibody in normal population [13].
Most reported cases of EM without PEo presented with headache and fever and were treated conservatively [5], or by the discontinuation of offending drugs [3, 4], except HL. The clinical features of our cases were similar to those of symptomatic cases besides multiple cranial neuropathies in case 1 , which was not reported in the literature. Although one patient (case 1) was treated with steroids, as other patients showed spontaneous improvement, steroid treatment may be reserved for later use in idiopathic EM without PEo.

To our knowledge, idiopathic EM without PEo has not been reported previously. Further studies are needed to investigate the mechanism of isolated CSF Eos without PEo.

\section{Disclosure Statement}

The authors declare that they have no vested interest that could be construed to have inappropriately influenced this study.

\section{References}

1 Kuberski T: Eosinophils in cerebrospinal fluid: criteria for eosinophilic meningitis. Hawaii Med J 1981;40:97-98.

$\checkmark 2$ Lo Re V 3rd, Gluckman SJ: Eosinophilic meningitis. Am J Med 2003;114:217-223.
3 Asperilla MO, Smego RA Jr: Eosinophilic meningitis associated with ciprofloxacin. Am J Med 1989;87:589-590.

44 Quinn JP, Weinstein RA, Caplan LR: Eosinophilic meningitis and ibuprofen therapy. Neurology 1984;34:108-109. 
5 Tsai HC, Liu YC, Kunin CM, Lee SS, Chen YS, Lin HH, Tsai TH, Lin WR, Huang CK, Yen MY, Yen CM: Eosinophilic meningitis caused by Angiostrongylus cantonensis: report of 17 cases. Am J Med 2001;111:109-114.

-6 Strayer DR, Bender RA: Eosinophilic meningitis complicating Hodgkin's disease. A report of a case and review of the literature. Cancer 1977;40:406-409.

7 Patchell R, Perry MC: Eosinophilic meningitis in Hodgkin disease. Neurology 1981;31: 887-888.
8 Hollister D Jr, Clements M, Coleman M, Petito F: Eosinophilic meningitis in Hodgkin's disease. report of a case and review of the literature. Arch Intern Med 1983;143: 590-592.

9 Calame JJ, van't Wout JW, van Dijk JG, Bots GT: A case of eosinophilic meningo-encephalitis accompanied by eosinophilic inflammation of the myenteric plexus in Hodgkin's disease. Histopathology 1986;10:535-539.
Weller PF, Liu LX: Eosinophilic meningitis. Semin Neurol 1993;13:161-168.

1 Chesney JC, Hoganson GE, Wilson MH: CSF eosinophilia during an acute coxsackie B4 viral meningitis. Am J Dis Child 1980;134: 703.

12 Simon D, Simon HU: Eosinophilic disorders. J Allergy Clin Immunol 2007;119:12911300; quiz 1301-1302.

13 Franceschini F, Cavazzana I: Anti-Ro/SSA and La/SSB antibodies. Autoimmunity 2005; 38:55-63. 